\title{
Internet or Store? An ethnographic study of consumers' internet and store-based grocery shopping practices
}

\begin{abstract}
Drawing on practice theory, this paper develops an understanding of the interrelationships between where and when consumers shop (the internet, stores, and their preferred retailers), and what they purchase (via the internet and in-store). Ethnographic case studies are presented of two consumers' internet and store-based shopping practices and how these intersect with their everyday lives, using data generated from multiple, complementary methods over an eighteen-month period. To this end, the paper contributes to the extant internet grocery shopping literature by offering a wider understanding of internet usage, as well as to broader debates surrounding retail change and shopping practices. The managerial implications of internet shopping on the contemporary retail grocery environment are also described and discussed.
\end{abstract}

Keywords: Grocery shopping, practice, internet, ethnography

\section{Introduction}


A significant proportion of UK consumers, currently estimated at $26 \%$, use grocery retailers' online shopping provisions on a regular, weekly or monthly, basis (Mintel, 2014). This represents a market worth $£ 8.9$ bn, which the Institute of Grocery Distribution predicts will more than double in size within 5 years (IGD, 2015). To date, however, little is known about how internet grocery shopping behaviour affects consumers' store-based choice repertoires, and vice versa (Calderwood and Freathy, 2014). Consequently, the focus of this paper is to explorethe interactions and dynamics between consumers' everyday internet and store-based grocery shopping behaviour and choices in particular consumption contexts.An understanding of such is particularly pertinent in the assessment of how, and to what extent, internet shopping is impacting on the vitality of the broader grocery retail landscape (see, Clarkeet al, 2006a).

Although there is a sizable amount of research that has focussed on online store choice, the majority of this research has however been conducted in sectors other than the grocery sector (Mortimer et al, 2016). Internet shopping for groceries, however, presents different consumption potentialities when compared to purchasing products that can be selected, transported, experienced, and even consumed online - as such as books, movies, and music (Rotem-Mindali and Weltevreden, 2013). Arguably, there remains a need to examine how consumers use the internet and stores interchangeably to purchase a basket of 'ordinary' goods (Warde, 2015), such as groceries, that are often heterogeneous and perishable (Hoyer et al, 2013).

Largely as a result of a limited range methodological approaches adopted in the extant literature,the research that has focussed on online grocery shopping (e.g. Chu et al, 2010; Dawes and Nenycz-Thiel, 2014; Gupa and Kim, 2007; Kim and Gupa, 2009) has tended to examine a particular facet of consumer behaviour, therebyunderplaying reciprocal natureof consumers' actual internet and store-based shopping practices. This is problematic as 
purchasing groceriesand related products can be best understood as being grounded within particular family/domestic relations, embedded in everyday routines, and intertwined within a nexus of related household practices and habits (Jackson et al,2006).

Drawing on practice-informed, ethnographic research, this papertherefore developsa understanding of the complex interrelationships between where and when consumers shop (the internet, stores, and their preferred retailers), and what they purchase(via the internet and in-store), as well as how this intersects with their everyday lives. Two richly contextualised case studies are presented that illustrate the internet and store-based grocery shopping behaviour and choices of individualsrepresenting nuanced family/household circumstances and domestic situations. In doing so, wereveal and unravel the embodied performances, tacit skills, and sophistication of consumers' everyday grocery shopping practices, how these are continually refined, modified, adjusted, and aligned to meet their respective grocery shopping requirements, and how retailers' internet shopping provisions are used - and become integrated into - their diverse and evolving shopping and related practices.To this end, this paper contributesto the extant grocery shopping literature by providing a broader understanding of internet usage, and addsto the wider debatesurrounding retail change and shopping practices (Alexander et al, 2009; Davies and Elliott, 2015; Elms andTinson, 2012).

In terms of structure, we begin with literature review that considers the implications of the internet on grocery retailing and on consumers' wider shopping practices. Following a brief discussion of our methodology, we report on two ideographic, individual-level ethnographic case studies of consumers'internet and store-based grocery shopping practices. We conclude by discussing the central findings of the study and its limitations, then outline the resulting managerial implications and consider the wider ramifications of this research in respect of the contemporary retail grocery environment. 


\section{The internet and grocery retailing}

Since the mid-1990s, researchers have begun to document the impact of the internet and e-commerce on retailing. Many early accounts heralded the internet as a method to offset the issues of order complexity and time costs inherent with other types of home delivery systems, such as telephone, catalogue and fax (Jones and Biasiotto, 1999; Reynolds, 1997; 1998). Grocery retailing was, therefore, considered likely to benefit from the 'death of distance' (Cairncross, 2001); an erosion of national borders and traditional retail market areas, as well as a reduction in the substantial costs of personnel, buildings and networks that accompany the physical distribution of goods and services (Clark and Wrigley, 1995).

Not surprisingly then, a central focus of retail academic research has been to examine how the internet threatens the high-street and traditional modes of retailing (e.g. Angelides, 1997; Wrigley et al. 2002; Doherty and Ellis-Chadwick, 2010). Although the impact on the high street has on the whole been moderate (Wrigley and Currah, 2006), internet-based shopping has affected some segments of the market much more than others - notably printing, publishing, music and entertainment. Retailers of specific product categories (such as computers and related devices, as well as white and brown goods) have also been hit hard by the internet with increasing numbers of consumers preferring to shop online rather than visit a store (Constantinides et al, 2008). Weltevreden (2007) suggests that this is a situation where the internet acts as a substitute or replacement for shopping in-store. Moreover, for retailers of other product categories, such as groceries, the impact on stores of online shopping was likely to remain limited until they were able to facilitate the experiential aspects of consumption online (see, Weltevreden and Van Rietbergen, 2009; Rotem-Mindali and Weltevreden, 2013). Burt and Sparks $(2003,284)$ have for instanced suggested that bricks and mortar stores might come to serve increasingly as display and marketing vehicles rather than locations of purchase. Research has emphasised that grocery retailers' internet 
shopping provisions remain heavily dependent on resolving the logistical problems posed by geographic space (Aoyama and Sheppard, 2003; LeinbachandBrunn, 2001; Ring and Tigert, 2001; Boschma and Weltevrenden, 2008) - the so-called 'last mile' problem (Fernieand Sparks, 2009).

The growing significance of consumers using the internet for grocery shopping purposes was detected in Clarke et al's study in Portsmouth [reported in Clarke et al, 2006b and Jackson et al, 2006 - as discussed below]. They concluded that, over a twenty-year period, consumer behavior had become increasing complex. Consumers were using a broad and diverse range of grocery retail provisions (specifically a combination of stores) to meet their household's grocery shopping requirements. Consistent with research focussing on consumer 'anti-choice' (e.g. Hogg et al, 2009) they also found that consumers were willing to abrogate stores that did not best reflect their changing lifestyles, needs and values. Wrigley (2010) considers this to be symptomatic of a broader shift in patterns of shopping behaviours aligned with an increasing desire for convenience retailing, including purchasing online.

Current market research suggests that consumers who shop online for groceries are typically from suburban, dual-income households, own or have access to one or more cars, are aged between 25-34 years old, and have children (Mintel, 2014). The limitedacademic research that has explored consumers' motivations for shopping online specifically for groceries(Morganosky and Cude, 2000;Rohm andSwaninathan, 2004; Liu et al., 2011),report that consumers prefer to use the internet as it offers them convenience and a minimal amount of effort (Chintaguntaet al, 2012). It also offers potentially lower prices and a wider selection of products compared to those on offer in-store (Chu et al, 2008). Such research has also found that online grocery shoppers are likely to be inclined to choose the same retailer as they purchase with in-store (Dawes and Nenycz-Thiel, 2014). A less familiar online shopping environment and higher perceived risk of purchasing online (Mortimer et al., 2016) 
requireconsumers to draw on their existing preferences and experiences when choosing an online provider for the first time. The assertion is that once consumers gain more experience of shopping online for groceries, other choice determinants become increasingly important, such as navigation, price, and product assortment (Melis et al., 2015), which may encourage them to shop using an alternative provider's online provisions.

Hand et al's (2009) investigation into the situational influences on consumers' online shopping behaviour provides a further reference point for this research. They suggested that step-changes in consumers' everyday lives, such as a serious illness or the birth of a child, might 'trigger' use of the internet for grocery shopping (Elms and Tinson, 2012; Dennis et al., 2016). Nevertheless, they emphasised that their respondents still tended to use grocery retailers' internet shopping provisions as a supplement to, rather than as a total replacement for, shopping in-store. Respondents appeared to discontinue purchasing groceries online once the initial trigger for change had disappeared. Accordingly, an understanding of how such internet purchasing impacts store-based behaviour and choices requires a consideration of the socially-embedded and situated nature of consumers' grocery shopping practices, as discussed below.

\section{Theories of social practice and shopping}

Theories of practice have a heterogeneous base (Schatzki et al, 2001), but present a useful lens to frame - and integrate - the social world. Although no single or authoritative version exists (Reckwitz, 2002), the broad principles and perspectives of practice theory have come to resonate across the breadth of the social sciences and humanities in recent years. Approached from this perspective, consumption choices are conceptualised as historically embedded, enacted cultural understandings and embodied performances that situate the multiple meanings and interpretations attached to them (Warde, 2015). 
Such work represents a marked departure from a focus on the symbolic meanings of conspicuous consumption, particularly its role in the construction, affirmation and display of consumers' self-styled identity projects (Gregsonand Crewe, 1997). It reinforces instead the social organisation of the mundane and the routine nature of everyday consumption (RandlesandWarde, 2006). Although often most comfortable in dealing with concepts such as routine, habit, and constraint (Warde, 2005), Shove et al (2012) suggest that theories of practice can also provide a mode of understanding of how behaviour evolves, recruits new participants to enable the continuation and transformation of practice, and how particular practices combine and become integrated with others (see also McMeekin and Southerton, 2012). Such work involves a consideration of specific moments of practice and their intersections between materials (such as technologies, including the internet), meanings and the degree of competence held by participating individuals.

Much research stresses that grocery shopping is a highly skillful, complexlygendered, socially-embedded and situated practice (Jackson and Holbrook, 1995; Miller,1998; Miller et al. 1998; Jackson, 2010; Jackson and Everts, 2010; Meah and Watson, 2013). Furthermore, consumption choices made after shoppers have traveled tostores involve complex, socially-constructed, notions of taste, value and quality. Such choices are, however, not so embedded that they cannot be changed as 'consumers are skillful, knowledgeable, and reflexive subjects, evolving a repertoire of store choice to fulfill their diverse requirements' (Jackson et al, 2006, p. 64). Jackson et al's(2006) research is central to our understanding of how different individual and household/domestic contexts constrain and enable the use of the internet as a shopping provision. Likewise,Gregson et al (2002, p. 607) suggest that 'weaving together' of generality (i.e. grocery shopping, e.g.) and particularity (using a particular provision, i.e. a store or via the internet) through practice reveals how shoppers make sense of different retail spaces and is also important to us. An understanding of the relationality, and 
inherent tensions, between internet shopping (both for grocery related items as well as other non-food products) and shopping by using stores is therefore necessary: all contextualized by the individual consumer's life-course (see Everts and Jackson, 2009; Bailey et al, 2010; Miller, 2012).

The above literature carries three main implications for our approach. First, there is a need to study the particular situations and contexts of consumers' day-to-day lives that lend themselves to using the internet as a mode of grocery shopping provision. Second, to emphasise the relationality between different modes of shopping as well as the linkages between consumption across spatial contexts, we acknowledge the significance of internetbased shopping choices but also linkages between internet shopping and shopping at stores. There is also a further choice to be made between competing retailers and between different formats/fascias of the same retail brand and between supermarket shopping and other retail formats. Thus, thirdly we seek an understanding of how consumers actively distinguish between different modes of shopping (and associated products or brands) and their social and cultural significance.

\section{Methodology}

This study is part of an on-going research project focussing on retail change and shopping behaviour in the Portsmouth/Havant area, located on the South coast of England. Adopting an ethnographic approach, two individual cases are presented in this study. Although the limitations of such an approach are discussed later in this paper, the 18-month data collection process generated an extensive dataset. These two cases enabled us to emphasise the nuances of the substantive issues under investigation and permitted 'maximized comparisons' (Sherry and Kozinets, 2001, 168). Our focus was on two shoppers 
who regularly used one or more of the supermarket multiples' internet provisions, but did not characterise the typical demographic profile of online grocery shoppers: 'Joan' and 'Justin'.'

Joan and Justin were both recruited via personal networks of the lead author. Neither had any previous formal interactions with any member of the study. Both Joan and Justin were fully briefed on the ethical commitments of the entire research team, and were incentivised to participate by being offered a cash payment of two hundred pounds. To facilitate the ethnographic goal of extended, experiential participation of the researcher in the specific life-world of the informant (Denzin and Lincoln, 2013), the lead author alone collected all of the empirical material. Consistent with the principles of grounded theory, the individual methods utilised were not prescribed from the outset of the research but rather directed by the phenomena under investigation and its evolving context (Glaser and Strauss, 1967). Ultimately, the data collection techniques involved combining, consumer focussed, complementary methods (Elliott and Jankel-Elliott, 2003). This included repeat face-to-face interviews, accompanied shopping trips, kitchen visits, shopping diaries, and consisted of four main phases.

The first phase involved undertaking two extended interviews conducted with the informants at their home, each lasting approximately two hours. The purpose here was to attempt to fulfil the primary ethnographic objective of becoming as 'experience-near' (Geertz, 1973) with each informant as possible. Using a very loosely structured interview guide, Joan and Justin's respective contribution to, and control over, the narrative was of central concern, with both asked to describe and discuss their in-store and internet grocery shopping practices. The issues and concerns identified during these initial interviews were defined, refined, and build upon throughout the remainder of the study.

${ }^{1}$ To ensure confidentially, all names used in this study are pseudonyms 
Acknowledging that shopping with consumers is a very useful research protocol for understanding of consumers' shopping experiences in-situ (Otnes et al, 1995), the second phase of the study involved accompanied shopping trips, both online and in-store. This also offered a 'rich experiential context' (Becker and Geer, 1970) to augment and to aid the interpretation of the informants' discursive accounts of their shopping behaviour. Whilst undertaking the online shopping trip, Joan and Justin where asked to talk aloud about their choices whilst shopping, and asked to reflect on their experiences after completing the online transaction. Adopting a similar design, the informants were also accompanied whilst shopping in-store, at a usual time and location. During this event, the informants were each asked to explain their choices as they shopped, which were recorded using an inconspicuous microphone. After the event, Joan and Justin were asked to reflect on their experience at the in-store café available on-site.

To capture a continuous stream of data, the third phase of the study involved the informants completing a 10-day food shopping diary. The diary was designed to capture both the informants' in-store and internet grocery shopping choices, and adhered to a semistructured format following guidelines recommended in the extant literature (see, Bartlett and Milligan, 2015). Joan and Justin were both provided guidelines on how to complete the diary, and were asked to document their thoughts, feelings, likes, and dislikes of their shopping experiences. The diary also provided both informants a further mechanism to record and reflect on their everyday shopping routines and practices (Meth, 2003). Utilising a similar structure to the food shopping diary, the informants also completed a further 10-day diary that was designed to record their internet usage, including their online grocery shopping practices, and their reflections thereof.

The fourth and final phase of the study involved undertaking a further two extended at-home interviews as well as kitchen visits with the informants. These were timed around 
when they were due to receive an online grocery delivery. A semi-structured interview guide was developed based on the content of empirical material collected in the previous stages of the study. These interviews provided Joan and Justin with a further opportunity to reflect on their grocery shopping practices and, critically, to consider how their habits and choices had changed throughout the full duration of the study period.

In preparation for analysis, each of the individual interviews tapes, as well as the recoding of the accompanied trips, were fully transcribed. To become familiar with the data, each transcript was then read and re-read several times by the lead author. At this juncture, Joan and Justin were provided with the opportunity to read their respective transcripts. Both however declined the offer. Spiggle's (1994) analytical framework was then used on the first phase interviews transcriptions to identify emerging thematic relationships. Following this, and adopting the logic of the 'constant comparison' method (Goulding, 2005, p. 297), the axial codes that emerged from the first phase interview data were systematically applied to entries contained in the grocery shopping diary, and then the internet usage diary to develop themes and categories (see, Jones, 2000). After discussions with the other two authors of this paper, and considering rival interpretations, as well as redefining provisional explanatory concepts, the transcriptions from the accompanied shopping trips and final phase interviews were analysed.

Given the ethnographic necessity of 'thick description' (Geertz, 1973), the empirical findings were collated as ideographic, individual level household cases. In doing so, we are able to present a detailed, intimate picture of these two individuals, and illustrate the interrelationship between where and when they shopped - and what they bought - as well as their household circumstances and domestic situations. 


\section{Findings:}

\section{Case study 1: “Joan"}

Joan, in her mid-fifties, lived alone. Because her only son, George, was on a round the world gap year he did not take part in this study. Her husband, Alec, had recently died. Joan began using the internet to shop for groceries when he fell ill, and she continued to do so after his death. Alec would habitually drive her to the supermarket but he became too ill to do so. Joan did not then hold a driving licence: making further supermarket visits difficult. George became Joan's next driver: including trips for grocery shopping. However, faced with the prospect of continued heavily reliance on George, Joan began shopping online with ASDA.com.

... I first started shopping online when Alec was in and out of hospital... it made sense... it meant that I didn't have to rely on him [George] to take me ... to see his dad and take me to the supermarket as well because I didn't drive... he said that he didn't want me to go on the bus or walk to ASDA... I didn't really want to or had the time... and arranging taxis was getting a little silly.

(At home interview)

Shopping online with ASDA.com at that time enabled Joan both to reduce the anxiety she associated with shopping and also to shop outside of hospital visiting hours which fitted with her new daily routines. Joan found bus transport to supermarkets involved tying herself down to fixed times - which she was unwilling to do especially as time had become an increasingly 'precious commodity... and food shopping wasn't really my number one priority' - reflective of one aspect of her emotional vulnerability.

Notwithstanding her very close relationship with George, as well as an extended network of kin and friends in the area, Joan also began shopping online as she didn't wish to be a 'further burden or be heavily dependent on other people around me'. Joan estimated that, soon, approximately three quarters of her total expenditure on food and related items was spent shopping with ASDA.com However, Joan revealed a number of situations where 
she preferred to shop in-store. Joan continued to make distinctions between items she was prepared to shop online for and others that she would not - as the following excerpts highlight:

... things like cereals, pasta, washing powder ... yes, [I'd buy them online] because they're bulky and the same no matter where you buy them... and it saves me carting them around with me... I tend to buy more day-to-day groceries for lunches and quick and easy meals... but not really things like fruit and vegetables because they tend to be different and if you buy too many they'll go to waste and I don't like wasting food... and because I want to pick out the nicest looking ones to get my money's worth... I'd only buy them [fruit and vegetables] if I knew I couldn't get to the supermarket.

And:

(Accompanied in-store shopping trip)

I've never been a great fan of buying meat online... items like meat you can never be sure of the quality.... I would rather go to ASDA instead, look myself or go to the butcher and get him to pick something nice for me.... I always went to ASDA to buy the beef joint for the Sunday roast when [Alec] was alive - because as it had to be special... because I wanted us to sit down properly as family...

(Kitchen visit)

Such judgements reflect both pragmatic, utilitarian evaluative measures (concerning the inherent qualities of a product, for example), and the extent to which Joan felt that she was expected to use her knowledge as a skilled shopper (Miller et al, 1998). Joan also called on trusted 'expert opinion' (DeVault, 1992) from the butcher when shopping in-store. The latter was used as a means to reduce the complexity and risk of the decision-making process; particularly when shopping for items imbued with moral and ethical overtones or that held deeply rooted social significance.

Joan typically purchased more 'bulky' household products and standardised food-stuffs online but when driven to ASDA by her son, Joan carefully evaluated specific products in order to 'pick something nice'. She perceived such products to be of variable quality - or in some other way 'different'. Such items were only ever purchased online when absolutely necessary. They included fresh or perishable foodstuffs since she was also seeking to avoid 
food wastage. There were also Joan's attempts to manage her expenditure on groceries and related items: to 'get [her] money's worth'. This is indicative of the socially-constructed peer pressure and the perceived need to be a 'good shopper' - another facet of Joan's emotional vulnerability.

To preserve the weekly ritual of the family Sunday lunch, Joan felt it essential to personally visit the supermarket to select the beef joint - the centrepiece of the meal. She could thereby avoid an incorrect decision that might fail to 'authenticate' (Arnould and Price, 2000) her desired performance as a 'good' wife and mother (Moisio et al, 2004). Such items are often regarded as 'special', and distinct practices cover what is served, how it is served, the time and energy that is put into the task, as well as who and what is included and excluded (see, Rook, 1985). The purchase of this symbolically-charged item is a manifestation of Joan's wish to enact culturally-bound customs of what is deemed proper, or what Elias (1978) refers to as 'civilised' behaviour. This traditional gender role stereotype, putting food as the focus of social interaction - and the consumption of certain prestige foods to signify social status - reinforces the emotional dimension of food.

Joan also described her use of her local Waitrose store, albeit much less frequently than she shopped with ASDA, either online or in-store. Consistent with Miller's (1998) distinction between shopping for 'treats' as against 'non-treats', Waitrose had a clearly defined role and purpose in Joan's shopping choice repertoire. It was reserved exclusively for the purchase of 'special' products for immediate consumption or 'rewards'.

I adore Waitrose's food, it's so tasty; classy food and drink... really good quality...I love the store because it is small and inviting, and the staff are always friendly and approachable, everything is laid out well ...It's great to shop there... but only for special things or rewards, when we were feeling down in the dumps.

(Kitchen visit) 
Following Alec's death, Joan had increasingly shopped at the Waitrose store for 'healthier' pre-prepared foods as she was not inclined cook meals 'from scratch' for herself and George, using fresh ingredients that she would have otherwise bought from ASDA. The purchase of such Waitrose products was a further attempt to successfully perform her role as a mother. They may have been convenience foods but they were also 'quality' and thus a valid coping mechanism during an extremely emotional and traumatic period. Later, Joan reverted to using ASDA as her main store, when, in her words: 'life had returned to some sort of normality'. Evidently, consumers make sophisticated adjustments to their shopping behaviour in light of changing household circumstances and life-course challenges (for other examples, see Mathur et al, 2008). Here, Joan's sense of self had been eroded after Alec's death and Joan faced an additional physical and emotional loss from George's departure to go travelling.

Joan also had an active social circle of friends to whom she had become closer after Alec's death. They provided her with emotional comfort and companionship, particularly since George had set out on his travels. These women, her 'ladies', took turns to organise a weekly 'meet-up' (usually a coffee morning) and a bi-monthly dinner party. The latter is often acknowledged as an activity reserved for the middle-classes to 'do friendships' (for other examples, see Paddock, 2015) through the consumption of food.

I had to laugh out loud the other day when a friend of mine said since she'd had her baby her husband said that they'd have to cut back on their outgoings... So now she can't do her regular Waitrose shop and now has to slum it at Sainsbury's - she's not happy!..she said to me "what am I going serve the ladies for dinner?" - she was appalled when I said that she was being silly and should try ASDA products!

(At home interview)

Although having described herself as 'financially secure', these comments suggest that Joan's grocery shopping practices were underpinned by issues of 'thrift' (Miller, 1998). This 
prevailed even though Joan understood that the 'meet up' was an opportunity to display distinctions in taste and social differentiation (Warde and Martens, 2000). This is reinforced by Joan's reference (above) to the friend who viewed Waitrose as the only sociallyrespectable place to shop: an assertion that Joan had refuted. This illustrates a tension between Joan's emotional vulnerability and the social values of her peer support at a time of food price increases.

Joan later returned to work on part-time basis for the first time since George had been born; not uncommon for women in a similar position, as highlighted by Hogg et al (2004). She had learned to drive yet continued to shop online despite her evident increase in personal mobility and better access to local store-based retailers. Indeed, she had begun shopping online with Tesco.com, preferring that to shopping at a local Tesco superstore. Joan explained:

Tesco is about a twenty minute drive from here [her home]. It's a bit out of the way ... and it is a little too near to the motorway for my liking. I've always used the ASDA near us... just out of habit I guess. But I will use Tesco.com as they offer a much wider range of products compared to ASDA [ASDA's online service].

(Accompanied online shopping trip)

As indicated in her grocery shopping diary, Joan felt uncomfortable driving for long distances, or at times when she knew there might be large volumes of traffic on the roads; she often 'waited for a good time... to avoid heavy traffic'. Due to her lack of self-confidence in her driving abilities she remained restricted in her choice of stores still preferring to shop at her nearby ASDA. The internet, of course, offered a respite - or refuge - from having to face the traffic at all. Indeed, Joan chose not to use the Tesco superstore or the larger ASDA/Walmart supercentre in the area since both were 'far too large... and I get far too confused as they sell everything... I get burned out with the choices'. This may be an example 
of what Schwartz (2004) refers to the 'paradox of choice' whereby too much choice can lead consumers to abrogate choice altogether and refuse to buy. The internet, conversely, only offered what Joan chose to seek.

Joan's use of Tesco.com may have been a form of variety-seeking behaviour but it also counterbalanced her internet-based shopping with ASDA.com.

When I started using Tesco.com... I had to think through what I was doing and how I went about shopping...it was quite weird buying for myself at first... I remember taking out several things that I thought George would like - but I had to keep telling myself: "he's not here".

(Accompanied online shopping trip)

Joan's use of Tesco.com aided her transition from a wife and mother, the shopper for a busy household, to that of a single woman. Her own preferences and tastes had previously been subordinated to those of the wider family - herself, Alec and George, a manifestation of love and devotion enacted through consumption (Miller, 1998). Joan's continued questioning of her internet based grocery shopping practices included 'adding and subtracting' and deleting George's preferred products and brands.

\section{Case study 2: “Justin"}

Justin, in his thirties, was a business manager at a services company and he lived in a house-share arrangement with two other professionals (though his girlfriend lived in London). From the outset of the research, Justin made it very clear that his use of the internet for grocery shopping purposes was an expression of his 'hatred' of supermarkets. He often voiced his frustrations towards what he saw as retailers' inefficient operational practices and their marketing efforts to entice and manipulate shoppers within their stores. 
I know why they [Tesco] keep changing their products around - it's to make you buy more... You'll go where you think something is and it's not there anymore, so you'll have to search for it and ended up buying something else while trying to do so.... ASDA is, quite frankly, appalling and I would never go.... Both of them are too big and too many people use them, yuk... I guess really that Sainsbury's is the lesser of all evils really, it's not good but much better than Tesco and ASDA - and of course... erm... it's just around the corner from here [his home].

(Kitchen visit)

Justin appeared to classify retailers in terms of distinctions based on symbolic and cognitive logic, or what Lévi-Strauss (1964) terms 'myths'. He used a particular Sainsbury's store, which was by no means exempt from criticism, because he considered this store to be the 'lesser of all evils'. Justin patronised Sainsbury's not just for its geographic proximity but because he also disliked smaller, independent retailers. Although Justin did like the discount retailers in the area, such as Aldi and Lidl, this was largely because such outlets were less busy - 'it's always really quiet'. Overall, though, he considered the discounters to be inferior toSainsbury's which he felt had greater visual appeal, better layout and availability of his preferred brands - including own brands. He noted:

I like Aldi... it's always really quiet... although it looks like a bomb site with everything laid out in no particular order... The quality is a bit hit and miss. Either it is terrible or really good it's sheer luck on the day... I'd generally rather go to Sainsbury's instead.

(Kitchen visit)

Justin had used Sainsbury's for internet shopping when he first went online but presently favoured Ocado. As with research on how the social connotations of physical space often mediate individuals' perception of virtual space (Dieberger, 2003), this was a direct reaction to his perceived grievances with his local Sainsbury's store. It also provided an understanding of why Justin rejected use of other grocery retailers' internet shopping systems. Justin explained his reluctance to use Waitrose as a desire not to taint his feelings 
towards Ocado (which, at the time, he believed was Waitrose's exclusive online shopping provision) with any negative experiences whilst shopping.

I like Waitrose's stuff very much - but I would never go out of my way to shop there... erm... I'd much rather use Ocado... as I don't want to get pissed off with the place and... erm... although I think Waitrose is lovely... it is other people, Christ almighty - I can't stand other shoppers!

(At home interview)

Justin's motivation for using the internet for grocery shopping lay not in the retail offer but was based on his dislike of fellow shoppers. This was a topic on which he elaborated when accompanied shopping in-store:

....I food shop online: so I don't have to put up with chavs, scalleys, old people and bloody screaming kids...I mean having to push past screaming kids and their stroppy looking mothers who'll have a go at you if their obnoxious brats make you wince and your ear bleed with their wailing - 'it's not their fault... they're only children'. Yeah, right, my nieces don't scream like that... ... this is why shopping online is fantastic, I mean I can get the majority of stuff that I want... without having to put up with a load of social reprobates and their screaming kids.

Justin's feeling towards the public space of the supermarket resembles Sartre's (1946/1989) maxim: 'hell is other people'. His 'shopping online is fantastic' is illustrative of his distaste for, avoidance of, and anxiety associated with, the 'crowd' (Penrose, 1952). He particularly disliked those he regarded as 'social reprobates', such as 'chavs' and 'scalleys' (popular cultural references for members of the UK's underclass - Jones, 2012). He also resented any shoppers who might impede his movements through the store, such as the elderly, mothers with prams, and young children. Concomitantly, through discursively drawing upon examples of his own upbringing and family behaviours in similar situations (such as his two young nieces), Justin attempted to socially distance himself from those referred to by Mead (1969) as 'generalized others'. 
Despite one accompanied shopping trip being conducted at a time and day that would normally be quiet, an untypically busy and crowded store led Justin to become visibly agitated and restless to the point where he considered abandoning the entire shopping trip.

OK, that's it. I've got to get out of here... I'll come back some other time... There's too many people, it's far too busy... I mean look at the length of this queue... I'm tempted to put half of this back... and grab a curry and some milk and I'll pay at the newspaper kiosk.

(Accompanied in-store shopping trip)

In a relatively short (thirty minute) period Justin displayed aggressive body language and walked rapidly around the store, weaving through the aisles in no particular order, backtracking and turning around when coming into contact with other shoppers. These are tactics that Goffman (1963) sees as 'involvement shields' (on several occasions Justin could be heard muttering: 'get out of $m y f^{* * * * * g}$ way'). In a follow up interview, Justin explained that his behaviour had been further fuelled by a shopper directly ahead of him in the checkout queue:

Why do women do that? It really cracks me up the number of occasions that the women in front of you in the check-out queue who have been waiting for ages and watching the people in front of them pack and pay, look like they'd been asked the meaning of life when the cashier asks them to pay. 'It is not hard love, have you ever been shopping before? Yes, that's right, a credit card will suffice'. Now give the card to the person behind the till or put your PIN in the machine. $\mathrm{OH}$ MY-GOD... that really winds me up....

(At home interview)

Justin's desire to leave the store quickly is indicative of his distaste for the mundane activity of shopping in supermarkets. Notwithstanding this uncomfortable shopping experience, and despite his reluctance to stop in-store, there were a number of situations when Justin used the Sainsbury's store rather than shopping online with Ocado. For example, he would 'hedge [his] bet to see if the supermarket wasn't full of retards': akin to research that has highlighted consumers' opportunistic behaviours whilst in immediate proximity to 
supermarkets (Bell and Lattin, 1998). Once, when he was primarily seeking a DVD, he discovered that the store was 'reasonably empty' and thus ventured further into the store to purchase discounted ready-meals:

Friday: 7pm - wanted to rent a DVD... went to Blockbuster Video - most of the good stuff was already out... Decided to go Sainsbury's and look at their collection of DVDs... ended up buying the Lost Boys... one of my favourite films for 4 quid - bargain! Store was reasonably empty... Saw Chinese ready meals were on offer - ' 2 for 1 ' so bought them too.

(Grocery shopping diary)

Conversely, Justin also revealed that he would 'actively go out of [his] way to avoid busy times' by shopping very early in the morning before work or late at night: indicative of how his store-based grocery shopping habits and routines were underpinned by efforts to 'shun' other shoppers. In other words, Justin planned his own behaviours in order to reduce the anxiety he could potentially experience whilst shopping in-store.

Justin was also keen to emphasise that he considered shopping online for groceries to be a 'different' activity from purchasing non-food items online:

I don't actually think that food shopping online is necessarily convenient per se... think about it, if I wanted to buy a CD for example the internet is convenient compared to going to say HMV in town.... if one of my favourites has released a new album I'll order it off Amazon or a similar website... a one off, single purchase... but with groceries it is different because you buy lots of different things... you have to think what you want for the next couple of weeks ahead and it takes a while to browse and buy... then normally a couple of more days until the man with the van comes to deliver everything... then if they have substituted items I'll either make do .. ...if it's not that important, or I'll end up going to the supermarket...

(At home interview)

The difference between 'a one off, single purchase' and the need to purchase many different items for the creation of meals required Justin to plan and organise himself in advance. He would then seek and select specific products - 'browse and buy' - from a multitude of alternatives over a significantly longer period of time online when compared to shopping in-store. Further distinctions also concerned issues surrounding the delivery of 
products to his home as well as the substitution of individual items. The latter would often involve a series of compromises where Justin, depending on his need for particular product, would either 'make do' or would go to Sainsbury's to purchase in-store. Both illustrate how deliberations and trade-offs - balancing the anxiety he felt in-store, particularly at busy times, with his need to purchase groceries - had become part of his shopping routines.

Moreover, Justin's ability to substitute individual items as well as his inability to anticipate, and 'forget' in some situations, his own needs are issues that he reflects upon when talking about having not to consider dependents, or an immediate 'family', whilst grocery shopping online.

The advantage [of shopping online] is that I do not have to go out to visit the shop... but most of all I always forget something as I do not think about the whole family and what is happening this week, Like last week I had a delivery... ordered Sun Pat peanut butter... I'd been eating it since I was a kid - but ....they'd substituted with their value brand peanut butter... I took it anyway. I'm happy that I did as it was lovely actually - and a big tub is half the price of small tub of Sun Pat... I'll be getting that again... but I've also had some rubbish stuff, like, erm... oh, yeah, like goats' cheese with blueberry instead of just goats' cheese... it was bloody awful - I palmed it off to Terry [his housemate].

(At home interview)

Through a process of what Franklin and Ebdon (2005) refer to as "incremental learning", it also emerged that the acceptance of substituted products prompted Justin to change his future purchasing behaviour and to minimise his resentment towards the supermarket chains. For example, if a successful substitution was made he would often specify the replacement product in the future. Conversely, if an inappropriate decision had been made he could simply 'palm [the item] off' to his housemates (thus he wouldn't feel 'too annoyed' with the retailer) but would avoid accepting such products during subsequent home deliveries. 
Domestic living arrangements such as those of Justin have often been seen as shortterm, transitional arrangements (Jarvis, 2011), or a consequence of economic constraints. Yet such house-share agreements are becoming increasingly adopted by younger professionals as they offer both financial and non-financial benefits. As Heath and Kenyon (2001) suggest, such non-traditional household forms appear to be appropriate for the needs and lifestyles of many individuals. They frequently need to juggle their conflicting personal and professional lives and are often considered to be constrained, or 'time poor' (Fenstermaker, 1996), when managing and organising their everyday lives. Justin documented several occasions when shopping online appeared to enable him to actively make time for other activities (de Kervenoael et al, 2014), illustrated by the extent that his internet shopping practices had become normalised within his domestic routines and leisure time, for example:

Monday: Booked the Ocado delivery for between $6-8 \mathrm{pm}$ it arrived at $7.30 \ldots$ While waiting spent 30 mins on the phone to my girlfriend - then started to iron my work shirts for next week (yuk!). I wanted to watch a DVD but didn't start it before the delivery came because I would have to stop it and start it over.... After the delivery I put the stuff away, finished off the ironing and started watching the film.

(Internet usage diary)

Although in the working week Justin 'fended for himself', at the weekend he considered his girlfriend's food and drink preferences when he shopped online. Observations of Justin using the internet revealed that he was in a much more calm and relaxed mood when compared to his in-store behaviours. Such was reflected in his reoccurring comments relating to 'how $f^{* * * * * g}$ brilliant [online shopping was]... no $f^{* * * * * g}$ people'. Moreover, as in Natalier's (2003) study of the division of domestic labour in shared households, whilst Justin and his housemates did not shop together, they did, however, occasionally buy some items on each other's behalf, particularly products that were to be used in domestic tasks and household chores. 
Monday: Bought $£ 64.24$ worth of groceries ( $+£ 5$ for delivery)... The majority for me but also bought some Green and Blacks dark chocolate and a couple of bottles of red wine for [his girlfriend] for when she's here at the weekend. Also [added] washing up liquid and dishwater tablets... (actually they are for my housemate his turn to pay - I'm hoping he'll give me the money back (;)...

(Grocery shopping diary)

Shopping both for his girlfriend and for his housemates was a means to 'bridge the boundaries' (Lister, 2004) between different households and a means to reinforce a series of very different social relationships, whilst at the same time attempting to manage the anxiety he associated with the in-store shopping environment.

\section{Discussion}

This paper has exploredthe interactions and dynamics between consumers' everyday internet and store-based grocery shopping behaviour and choices. The two in-depth examples of Joan and Justin have illustrated how consumers use multiple forms of retail provision (the internet, stores, and their preferred retailers), and how these combine to meet their everyday grocery shopping requirements. These two case studies do not represent the ideal-typical profile of online grocery shoppers as identified in commercial research, therefore adding to a wider understanding of internet usage.

Through theoretically framing these ethnographic case studies through the lens of practice, this paper has developed an understanding of the interrelationships between where and when consumers shop (the internet, stores, and their preferred retailers), and what they purchase (via the internet and in-store), and how this intersects with their everyday lives. In doing so, this paper also contributes to the extant internet grocery shopping literature by exemplifying the complexities and reciprocal nature of consumers' internet and store-based shopping behaviour and choices. 
With Joan, we noted how her shopping behaviour changed around the time of the death of her husband, adding a dimension - not pursued here - that is more commonly found in research on the recently bereaved (Gentry et al, 1995; Metcalf and Huntington, 1991). Suffice it that for Joan it changed how she used stores, her choice of home delivery service and, with that, which retailers she preferred. Justin's accounts of his shopping practices, his shopping behaviours in-store and via the internet, resonate more with the literature on the anxieties and fears that some individuals experience when shopping in the public spaces of the supermarket (Jackson, 2010; Jackson and Everts, 2010; Miller, 1998). This case vividly illustrated the stresses that Justin experienced when shopping in-store and revealed the internet as a haven from such experiences. We also uncovered his attempts to manage and organise his everyday life as a single man within the benefits and constraints of shared household living.

Consistent with research which has emphasised the cultural significance of the acts of shopping (Crewe and Gregson, 1998; Gregson and Crewe, 1997; Jackson and Holbrook, 1995; Miller, 1998; Miller et al, 1998), this paper highlights the multiple and situated meanings that the informants attached to their grocery shopping geographies and consumption practices as they are expressed both in-store and via the internet. To this end, we have revealed underlying narratives of gender, class, family, and kinship across the two cases. Moreover, these empirical accounts also illustrated how the informants related to - and distinguished between - particular retail spaces, in this instance, stores and at home using the internet, different modes of shopping (in-store and via the internet) and products, e.g. groceries and non-food items (Gregson et al. 2002).

The novel ethnographic case studies presented in this paper have also revealed and unravelled the embodied performances, tacit skills, and sophistication of the informants' everyday grocery shopping practices. These were continually refined, modified, adjusted and 
aligned to meet their respective grocery shopping requirements. Akin to research that has emphasised the socially-embedded and situated nature of consumers' store-based purchasing behaviour (Jackson et al, 2006), as well as research that has highlighted the dynamics of practice (Shove et al, 2012), we have provided examples of how retailers' internet shopping provisions are used - and have become integrated into - the informants' diverse and evolving shopping and related practices. In both cases, the informants' shopping practices (both online and in-store) were flexible and tailored towards the idiosyncratic, or, in the case of Joan, the more discontinuous, changes that occurred in their individual, and household circumstances and domestic situations.

Note, too, that some research has suggested that consumers are likely to discontinue their use of the internet for grocery shopping purposes following the resolution of whatever life event prompted its initial uptake (Hand et al, 2009). For our informants, conversely, after a sustained period of use, shopping via the internet for groceries became an embedded part of both Joan and Justin's routines. Indeed, we have no reason to suppose that Justin's antipathy towards large stores, nor Joan's dislike of heavy traffic are nearing an end. Joan and Justin's use of internet as refuge enabled them to avoid the likelihood of an unpleasant shopping experience either at store or en route to it. In the case of Joan, it added the benefit of not having to face too much in-store choice. That said, due to perishability and other inherent characteristics of grocery and related items, they also continued - albeit at times of their choosing - to use grocery stores alongside food purchasing via the internet. So, the internet complemented rather than replaced the informants' store-based grocery shopping behaviour and choices (Weltevreden and Van Rietbergen, 2009). By combining their use of the internet and stores in this way, both empirical cases still reveal the broader prevalence of 'convenience culture' in retailing (Wrigley, 2010) and thus add to the broader debates surrounding retail change and shopping behaviour. 


\section{Limitations and suggestions for further research}

Even taken together, our two case studies may seem a limited basis from which to draw wider conclusions. This apparent drawback should, however, be seen in the light of the extremely time-intensive methodology that we chose and which drew out novel and richly contextualised empirical insights. Accompanying the respondents whilst in-store and online enabled us to confirm that, as others have found, the experience of grocery shopping online is every bit as personal and complex as store-based shopping. Subsequent anecdotal observations - and existing parallel research (***** and ***** 2012) - also confirm our findings of dissatisfaction with some of the very largest store formats. We may also consider the topics that we might have explored further had time constraints not been a factor. Firstly, we might have looked more closely at the precise in-store factors that caused distress to our respondents. As noted, crowding is currently being increased by staff store-picking for home delivery. Some layouts, too, seem to invite interpersonal conflict. In July, 2012, one of the stores under investigation in Clarke et al's (2006b) study acted to separate out those who wish to buy small quantities of food from those queuing simply to buy cigarettes and lottery tickets. Checkout issues were especially a problem for Justin and deserve further scrutiny. More attention, too, needs to be paid to the battleground of shelf-layout where retailer own brand and value ranges compete with branded goods. Note, too, that our focus on the larger formats means that this research largely ignored the 'new' convenience sector where Tesco and Sainsbury were early movers. Many such stores can be accessed without use of a car and may be ideal for the smaller, single-person-household, purchase pattern.

This paper has developed an understanding of the complex interrelationships between where and when consumers shop (the internet, stores, and their preferred retailers), and what they purchase(via the internet and in-store), as well as how this intersects with their everyday lives. Nevertheless, additional research that involves a more diverse group of case studies 
would allow for an increased understanding of the particular individual and household circumstances, and domestic situations, that lend themselves to the initial usage of the internet as a grocery shopping provision, and how these mediate the interactions between shopping behaviourand choices online and in-store. This could involve consumers from different social-economic groups, urban and rural settings, age-profiles, and family and household compositions. The role and influence of other family/household members, such as children, partners/spouses, and housemates in a main shoppers' internet and store-based grocery shopping practices could also benefit from elaboration in future research.

\section{Conclusions and implications}

Here we focus specifically on what our findings may tell us about longer term food retail trends should internet grocery shopping actually proceed at the pace predicted by IGD. For Justin in particular, the ambience of large, one-stop foodstores inherently created problems. The current, very visible, rise in the numbers of store staff delegated to picking items for home delivery may exacerbate in-store congestion to a point that it further deters relaxed shopping: it may even have been an unspoken factor in Justin's distress. This suggests the need to re-think that practice or to go to dedicated fulfilment centres (the Ocado model). Note that when shoppers defect from crowded stores and instead shop online for home delivery then they pass the cost of delivery back to the retailer - hence the popularity with retailers of 'click and collect'. Indeed 'click and collect' solves Justin's reluctance to venture in-store but would leave Joan with the task of finding a suitably quiet time to drive to collect. 'Click and collect' holds the further advantage that the customer has chosen to be tied into a trip purchase with a specific retailer and is unlikely to defect to another en route. It does not, however, solve the problem that they also absent themselves from in-store impulse purchase possibilities. 
As signalled at the outset of this paper, internet shopping for groceries is now no longer reserved for a limited demographic of UK consumers. Our two case studies illustrated the multiple social opportunities for consumers of using retailers' internet shopping provisions in combination withstores, albeit for very different reasons. To capitalise on the projected growth in the online grocery market, retailers should craft targeted marketing messages that emphasisehow combining the use of their internet grocery shopping provisions and their stores can offer consumers a 'lifestyle solution' to a diverse variety of different individual and household needs, given their particular pragmatic, geographic, and domestic circumstances.

\section{References}

Alexander A, Nell D, Bailey A, and Shaw G, (2009), "The co-creation of a retail innovation: shoppers and the early supermarket in Britain", Enterprise and Society, Vol. 10, Issue 3, pp. 529-558

Angelides, M, C. (1997), "Implementing the internet for business: a global marketing opportunity”, International Journal of Information Management, Vol. 17 No. 6, pp. 405-419

Aoyama, Y.and Sheppard, E. (2003), "The dialectics of geographic and virtual space, Environment and Planning”, Vol. 35 No. 7, pp. 1151-6

Arnould, E. and Price, L. (2000), "Authenticating acts and authoritative performances: questing for self and community",in Ratneshwar, S. Mick, D and Huffman, C. (Eds) Why of Consumption, Routledge: NY, New York, pp. 140 - 163.

Bailey, A., Shaw, G., Alexander, A., and Nell, D. (2010), "Consumer behaviour and the life course: shopper reactions to self-service grocery shops and supermarkets in England c.1947-75”, Environment and Planning A, Vol. 42 No. 6, pp. $1496-1512$

Bartlett, R., and Milligan, C, (2015), What is Diary Method, London: Bloomsbury

Becker, H., and Geer, B, (1970), "Participant observation and interviewing: A comparison", in W. Filstead (ed.), Qualitative Methodology, Chicago: Rand McNally, pp. 133-142

Bell, D and Lattin J (1998), "Shopping behaviour and consumer preference for store price format: why "large basket" shoppers prefer EDLP" Marketing Science, Vol. 17, Issue 1 , pp. $66-68$

Boschma, R., and Weltevreden, J. (2008), “An evolutionary perspective on Internet adoption by retailers in the Netherlands", Environment and Planning A, Vol. 40 No. 9, pp. $2222-2237$

Burt S., and Sparks, L., (2003), "E-commerce and the retail process: a review", Journal of Retailing and Consumer Service, Vol. 10 No. 5, pp. 275-286

Cairncross, F. (2001) The Death of Distance 2.0: How the Communications Revolution will Change our Lives, Texere, London 
Calderwood, E., and Freathy, P. (2014), "Consumer mobility in the Scottish isles: the impact of internet adoption on retail travel patterns", Transportation Research Part A: Policy and Practice, Vol. 59, pp. $192-203$

Chintagunta, P., Chu, J., and Cebollada, J, (2012), "Quantifying transaction costs in online/off-line grocery channel choice”, Marketing Science, Vol. 31 Issue 1, pp. 96114

Chu, J., Arce-Urriza, M., Cebollada, J., and Chintagunta, P. (2010),“An Empirical Analysis of Shopping Behavior Across Online and Offline Channels for Grocery Products: The Moderating Effects of Household and Product Characteristics",Journal of Interactive Marketing, Vol. 24 Issue 4, pp. 251-268

Chu, J., Chintagunta, P., and Cebollada, J, (2008), "Research note - A comparison of within-household price sensitivity across online and offline channels",Marketing Science, Vol. 27 Issue 2, pp. 283-299

Clark, G., and Wrigley, N. (1995), 'Sunk costs: a framework for economic geography', Transactions of the Institute of British Geographers, Vol. 20 No. 2, pp. 204-12

Clarke I, Hallsworth A, de Kervenoael R, (2006a), "Macro-level change and micro-level effects: A twenty year perspective on changing grocery shopping," Journal of Retailing and Consumer Services, Vol. 16, No. 6, pp. 381-392

Clarke, I., Hallsworth, A., Jackson, P., de Kervenoael, R., del Aguila ,R.P, and Kirkup, M. (2006b), "Retail restructuring and consumer choice 1. Long-term local changes in consumer behaviour: Portsmouth, 1980 - 2002”, Environment and Planning, Vol. 38 No. 1, pp. $25-46$.

Constantinides, E., Romero, C., and Boria, M. (2008), "Social media: a new frontier for retailers?", European Retail Research, Vol. 22, pp. 1 - 28

Couclelis, H. (2004), "Pizza over the internet: e-commerce, the fragmentation of activity and the tyranny of the region", Entrepreneurship and Regional Development, Vol. 16, pp. $41-54$

Davies A, and Fitchet, J, (2015), "In the family way: bridging a mother-daughter (matrilineal) perspective to retail innovation and consumer culture" Environment and Planning A, Vol. 47, pp. 727-743

Dawes, J., and Nenycz-Thiel, M. (2014), "Comparing Retailer Purchase Patterns and Brand Metrics for In Store and Online Grocery Purchasing", Journal of Marketing Management, Vol. 30 Issue 3/4, pp. 364-382

deKervenoael, R., Elms, J., and Hallsworth, A, (2014), "Influencing online grocery innovation: Anti-choice as a trigger for activity fragmentation and multi-tasking", Futures, Vol. 62, Part B, pp. 155-163.

Dennis, C., Alamonos, E., Papagiannidis, S., and Bourlakis, M. (2016), "Does social exclusion influence multiple channel use? The interconnections with community, happiness, and well-being", Journal of Business Research, Vol. 69, Issue 3, pp. 10611070

Denzin, D., and Lincoln, Y, (2011), The SAGE Handbook of Qualitative Research, Thousand Oaks, CA: Sage.

DeVault, M. (1992). Feedings the Family: The Social Organization of Caring as Gendered Work. University of Chicago, Press Chicago, IL

Dieberger, A. (2003), "Social connotations of space in the design for virtual communities and social navigation", in Hook, K, Benyon, D and Munro, A (Eds), Designing Information Spaces: The Social Navigation Approach, Springer, London, pp. 293 313 
Doherty, N., and Ellis-Chadwick, F. (2010), "Internet retailing: the past, the present and the future", International Journal of Retail and Distribution Management, Vol. 38 No. $11 / 12$, pp. $943-965$

Elias, N, (1978), The Civilizing process - The History of Manners, New York, Pantheon Books

Elliott, R., and Jankel-Elliott, N. (2003), "Using ethnography in strategic consumer research", Qualitative Market Research: An International Journal, Vol. 6 No. 4, pp. 215 - 223

Elms, J., and Tinson, J. (2012), "Consumer vulnerability and the transformative potential of internet shopping: an exploratory case study", Journal of Marketing Management, Vol. 28 No. $11 / 12$, pp. $1354-1376$

Everts, J., and Jackson, P. (2009), "Modernisation and the practices of contemporary food shopping", Environment and Planning D: Society and Space, Vol. 27 No. 5, pp. $917-935$

Fenstermaker, S. (1996), “The dynamics of time use: context and meaning”, Journal of Family and Economic Issues, Vol. 17 No. 3-4, pp. 231 - 243

Fernie, J., and Sparks, L. (2009). Logistics and Retail Management: Emerging Issued and Challenges. Third Edition, Kogan Page, London

Franklin A, and Ebdon C, (2005), "Practical experience: Building bridges between science and practice," Administrative Theory and Praxis Vol. 27, Issue 4, pp. 628 - 649

Geertz, C, (1973), The Interpretation of Cultures, London: Basic Books

Gentry, J., Kennedy., and Hill, P., (1995), "Family transitions during grief: Discontinuities in household consumption patterns", Journal of Business Research, Vol. 34 Issue 1, pp. 67-79

Glaser, B., and Strauss, A. (1967), The Discovery of Grounded Theory: Strategies for Qualitative Research. Aldine, Chicago, IL

Goffman, E. (1963), Behavior in Public Places: Notes on the Social Organisation of Gatherings, Collier Macmillan, London

Goulding, C. (2005), "Grounded theory, ethnography and phenomenology: a comparative analysis of three qualitative strategies for marketing research", European Journal of Marketing, Vol. 39 No. 3/4, pp. $294-308$

Gregson, N., and Crewe, L. (1997), "The bargain, the knowledge, and the spectacle: making sense of consumption in the space of the car-boot sale", Environment and Planning. D: Society and Space, Vol. 15 No. 1, pp. $87-112$

Gregson, N., and Crewe, L., (1998), "Dusting down 'second hand rose': gendered identities and the world of second-hand goods in the space of the car boot sale", Gender, Place and Culture, Vol. 5, pp. $77-100$

Gregson, N., Crewe, L., and Brooks, K. (2002), "Shopping, space, and practice, Environment and Planning D: Society and Space”, Vol. 20 No. 5, pp. 597 - 617

Gupta, S., and Kim, H. (2007), "The Moderating Effect of Transaction Experience on the Decision Calculus in On-line Repurchase", International Journal of Electronic Commerce, Vol. 12 Issue 1, pp. 127-158

Hand, C., Dall'Olmo Riley, F., Harris, P., Singh, J., and Rettie, R. (2009), “Online grocery shopping: the influence of situational factors", European Journal of Marketing, Vol. 43 No. 9/10, pp. $1205-1219$

Heath, S. and Kenyon, E, (2001), "Choosing this life: narratives of choice amongst house sharers", Housing Studies, Vol. 16 No. 5, pp. 619 - 635

Hogg, M., Banister, E., and Stephenson, C. (2009), "Mapping symbolic (anti-) consumption, Journal of Business Research”, Vol. 62 No. 2, pp. 148 - 159 
Hogg, M., Curasi, C., and Maclaran, P. (2004), "The (re-)configuration of production and consumption in empty nest households/families", Consumption, Markets and Culture, Vol. 7 No. 3, pp. $239-259$

Hoyer, W., MacInnis, D., and Pieters, R. (2013), Consumer Behavior, $6^{\text {th }}$ Edition, Stamford: CT: Cengage Learning.

IGD. (2015), Online Shopping.Letchmore Heath, Watford IGD

Jackson, P. (2010), "Food stories: consumption in an age of anxiety", Cultural Geographies, Vol. 17 No. 2, pp. 147-165

Jackson, P., and Everts, J. (2010), “Anxiety as social practice”, Environment and Planning, Vol. 42 No. 11, pp. $2791-2806$.

Jackson, P., and Holbrook, B. (1995), "Multiple meanings: shopping and the cultural politics of identity", Environment and Planning A, Vol. 27 No. 12, pp. 1913 - 1930

Jackson, P., del Aguila, R.P., Clarke, I., Hallsworth, A., de Kervenoael, R., and Kirkup, M. (2006), "Retail restructuring and consumer choice 2. Understanding consumer choice at the household level", Environment and Planning, Vol. 38 No. 1, pp. 47 - 67

Jarvis, H, (2011), "Saving space, sharing time: integrated infrastructures of daily life in cohousing", Environment and Planning A, Vol. 43 Issue 5, pp. 560-577

Jones, K., and Biasiotto, M. (1999), "Internet retailing: current hype or future reality?",International Review of Retail, Distribution and Consumer Research, Vol. 9, pp. 69-79

Jones, O, (2012), Chavs: The Demonization of the Working Class, London: Verso Books

Jones, R, (2000), "The unsolicited diary as a qualitative tool for advanced research capavity in the filed of health and illness", Qualitative Health Research, Vol. 10 Issue 4, pp. 555-567

Kim, H., and Gupta, S., (2009), "A Comparison of Purchase Decision Calculus Between Potential and Repeat Customers of an Online Store", Decision Support Systems, Vol. 47 Issue 4, pp. 477-487

Leinbach, T.R., and Brunn, S.D. (2001), Worlds of E-commerce: Economic, Geographical and Social Dimensions. Wiley, London

Levi-Strauss, C. (1964), Mythogiques, Le Cru et Le Cuit. Trans. E. Leach. Penguin Books, London

Lister, D. (2004), "Young people's strategies for managing tenancy relationships in the private rented sector", Journal of Youth Studies, Vol. 7 No. 3, pp. $315-330$

Liu, C., Forsythe, S., and Black, W.C. (2011), "Beyond adoption: sustaining online shopping", International Review of Retail, Distribution and Consumer Research, Vol. 21 No. 1 pp. 71-93

Mathur, A., Moschis, G., and Lee, E. (2008), "A longitudinal study of the effects of life stages on changes in consumer preferences", Journal of the Academy of Marketing Science, Vol. 36 No. 2, pp. $234-246$

McMeekin, A., and Southerton, D. (2012), "Sustainability transitions and final consumption: Practices an sociotechnical systems", Technology Analysis and Strategic Management, Vol. 24, pp. 345-361.

Mead G, (1969), Play, the Game, and the Generalized Other, New York: Holt Rinehart and Winston

Meah, A., and Watson, M, (2013), “Cooking up consumer anxieites about 'provenance' and ethics': Why it sometimes matters where food comes from in domestic provisioning", Food, Culture and Society, Vol. 16, pp. 495-512

Melis, K., Campi, K., Breugelmans, E., Lamey, L. (2015), "The impact of the multichannel retail mix on online store choice: Does online experience matter?",Journal of Retailing, Vol. 91 Issue 2, pp. 272-288 
Metcalf P, and Huntington R, (1991), Death: The Anthropology of Mortuary Ritual $2^{\text {nd }}$ edition, Cambridge: Cambridge University Press

Meth, P, (2003), "Entries and omissions: Using solicited diaries in geographical research", Area, Vol. 35 Issue 2, pp. 195-205

Miller, D. (1998), A Theory of Shopping, Polity Press, Cambridge

Miller, D. (2012), Consumption and its Consequences. Polity Press, Cambridge.

Miller, D., Jackson, P., Thrift, N., Holbrook, B., and Rowlands, M. (1998) Shopping, Place and Identity.Routledge, London

Mintel. (2014), Online Grocery Shopping. Mintel Oxygen Reports, London

Moisio, R., Arnould, E., and Price, L. (2004), "Between mothers and markets: constructing family identity through homemade food", Journal of Consumer Culture, Vol. 4 No. 3 , pp. $361-384$

Morganosky, M., and Cude, B. (2000), "Consumer response to online grocery shopping", International Journal of Retail and Distribution Management, Vol. 28 No. 1, pp. 1726.

Morganosky, M., and Cude, B. (2000), "Consumer response to online grocery shopping", International Journal of Retail and Distribution Management, Vol. 28 No. 1, pp. 1726.

Mortimer, G., Hasan, S., Andrews, L., and Martin, J., (2016), "Online grocery shopping: the impact of shopping frequency on perceived risk", International Review of Retail, Distribution and Consumer Research, Vol. 26 Issue 2, pp. 202-223.

Natalier, K. (2003), "I'm not his wife': doing gender and doing housework in the absence of women", Journal of Sociology, Vol. 39 No. 3, pp. $253-269$

Otnes, C., McGrath, M., and Lowrey, T, (1995), "Shopping with consumers usage as past, present and future research technique", Journal of Retailing and Consumer Services, Vol. 2 Issue 2, pp. 97-110

Paddock, J, (2015), “Invoking simplicity: 'alternative' food and the reinvention of distinction", SociologiaRutalis, Vol. 55 Issue 1, pp. 22-40

Penrose, L. (1952), On the Objective Study of Crowd Behavior. HK Lewis, New York, NY

Randles, S., and Warde, A. (2006), "Consumption: the View from Theories of Practice", in Green, K and Randles, S (Eds), Industrial Ecology and Spaces of Innovation, Edward Elgar, Cheltenham, pp. 220-237

Reckwitz, A. (2002), "Towards a theory of social practices", European Journal of Social Theory, Vol. 5 No. 2, pp. $243-263$

Reynolds, J. (1997), "Retailing in computer-mediated environments: electronic commerce across Europe", International Journal of Retail and Distribution Management, Vol. 25 , pp. 29-37

Reynolds, J. (1998), “Opportunities for electronic commerce”, European Retail Digest, Vol. 18 , pp. 5-9.

Ring, L. and Tigert, D. (2001), "Viewpoint: the decline and fall of Internet grocery retailers", International Journal of Retail \& Distribution Management, Vol. 29 No. 6, pp. $264-$ 271

Rohm, A., and Swaninathan, V. (2004), "A typology of online shoppers based on shopping motivations, Journal of Business Research, Vol. 57 Issue 7, pp. 748-757

Rook D, (1985), “The ritual dimension of consumer behaviour" Journal of Consumer Research, Vol. 12 (December), pp. $251-269$

Rotem-Mindali, O., and Weltevreden, J.W. J. (2013), “Transport effects of e-commerce: what can be learned after years of research?",Transportation, Vol. 40, pp. 867-885

Sartre, J-P. (1946/1989), No Exit and Other Plays. Vintage International, New York, NY 
Schatzki, T., Knorr-Cetina, K., and Von Savigny, E. (2001), The Practice Turn in Contemporary Theory. Routledge, London

Schwartz, B. (2005), The Paradox of Choice: Why More is Less. Perennial Harper, New York, NY

Sherry, J., and Kozinets, R. (2001), "Qualitative inquiry in marketing and consumer research", in Iacobucci, D (Ed), Kellogg on Marketing. John Wiley, New York, NY, pp. $165-194$

Shove, E., Pantzar, M., and Watson, M. (2012).The Dynamics of Social Practice.Sage, London

Spiggle, S, (1994), "Analysis and interpretation of qualitative data in consumer research", Journal of Consumer Research, Vol. 21 Issue 3, pp. 491-503

The Grocer. (2012), "Tesco calls an end to the space race", $13^{\text {th }}$ October, pp. 21.

Warde A, Martens L, (2000), Eating Out: Social Differentiation, Consumption and Pleasure, Cambridge:Cambridge University Press

Warde, A (2015), "The Sociology of Consumption: Its recent development", Annual Review of Sociology, Vol. 41, pp. 117-134

Warde, A. (2005), "Consumption and theories of practice", Journal of Consumer Culture, Vol. 7 No. 5, pp. $131-153$

Weltevreden, J.W.J. (2007), "Substitution or complementarity? How the internet changes city centre shopping”, Journal of Retailing and Consumer Services, Vol. 14 No. 3, pp. 192-207

Weltevreden, J.W.J., and Van Rietbergen, T. (2009), "The implications of e-shopping for instore shopping at various shopping locations in the Netherlands", Environment and Planning B: Planning and Design, Vol. 36 No. 2, pp. 279-299

Wrigley, N. (2010), "The globalization of retail capital: themes for economic geography", in Clark, G.L., Feldman, M. and Gertler, M.S., (Eds), The Oxford Handbook of Economic Geography, Oxford University Press, Oxford, pp. 292-313.

Wrigley, $N$., andCurrah, A. (2006), "Globalizing retail and the e-conomy: the organizational challenge of e-commerce for retail TNCs", Geoforum, Vol. 37 No. 3, pp. $340-351$.

Wrigley, N., Lowe, M., and Currah, A. (2002), "Retailing and e-tailing", Urban Geography Vol. 23 No. 20, pp. 180-197 